\title{
Trends in cutaneous malignant melanoma in Sweden 1997-2011: Thinner tumours and improved survival among men
}

\author{
Johan Lyth, H. Eriksson, J. Hansson, C. Ingvar, M. Jansson, J. Lapins, E. Månsson-Brahme,
}

P. Naredi, U. Stierner, G. Ullenhag, John Carstensen and C. Lindholm

\section{Linköping University Post Print}

\section{Tweet}

N.B.: When citing this work, cite the original article.

Original Publication:

Johan Lyth, H. Eriksson, J. Hansson, C. Ingvar, M. Jansson, J. Lapins, E. Månsson-Brahme, P. Naredi, U. Stierner, G. Ullenhag, John Carstensen and C. Lindholm, Trends in cutaneous malignant melanoma in Sweden 1997-2011: Thinner tumours and improved survival among men, 2015, British Journal of Dermatology, (172), 3, 700-706.

http://dx.doi.org/10.1111/bjd.13483

Copyright: Wiley: 12 months

http://eu.wiley.com/WileyCDA/

Postprint available at: Linköping University Electronic Press http://urn.kb.se/resolve?urn=urn:nbn:se:liu:diva-113143 


\title{
Trends in cutaneous malignant melanoma in Sweden 1997-2011:
}

\section{Thinner tumours and improved survival among men.}

\author{
J. Lyth ${ }^{1,2}$, H. Eriksson ${ }^{3}$, J. Hansson ${ }^{3}$, C. Ingvar ${ }^{5}$, M. Jansson ${ }^{6}$, J. Lapins ${ }^{4}$, E. Månsson- \\ Brahme $^{3}$, P. Naredi ${ }^{7}$ U. Stierner ${ }^{8}$, G. Ullenhag 9 , J. Carstensen ${ }^{10}$, C. Lindholm ${ }^{2}$ \\ ${ }^{1}$ Department of Clinical and Experimental Medicine, Linköping University, Linköping \\ ${ }^{2}$ Regional Cancer Center South East, University Hospital, Linköping \\ ${ }^{3}$ Department of Oncology-Pathology, Karolinska Institute, Stockholm \\ ${ }^{4}$ Department of Dermatology, Karolinska University Hospital, Stockholm \\ ${ }^{5}$ Department of Surgery, Lund University Hospital, Lund \\ ${ }^{6}$ Department of Surgery, Umeå University, Umeå \\ ${ }^{7}$ Department of Surgery, University of Gothenburg, Sahlgrenska University Hospital, Göteborg \\ ${ }^{8}$ Department of Oncology, Sahlgrenska University Hospital, Göteborg \\ ${ }^{9}$ Department of Radiology, Oncology and Radiation Science, Section of Oncology, Uppsala University, Uppsala \\ ${ }^{10}$ Department of Medical and Health Sciences, Linköping University, Linköping \\ Correspondence to: Johan Lyth, Regional Cancer Center South East, University Hospital, Linköping,
} S-58185 Linköping, Sweden.

Phone: +46-10 1033488, Fax: +46-10 1032846

E-mail: johan.lyth@liu.se

Short title to be used as a 'running head': Trends in CMM in Sweden 1997-2011

Conflicts of Interest and Source of Funding: No conflicts of interest were declared from the authors.

Word count Abstract: 240 Word count Text: 2 716, tables: 2+6 suppl., figures: $3+2$ suppl.

Bulleted statements: what's already known about this topic; 1. Patient survival and the proportion of thin CMM has been rising over time in most Western countries, though the corresponding rate of improvement of survival appears to have declined in Sweden at the end of the last millennium. what does this study add; 1 . Swedish nationwide time trends of tumour thickness in CMM have been analysed for the first time 2. A shift over time towards thinner CMMs for men was accompanied by $19 \%$ improved 5-year CMM-specific survival. 3. Corresponding changes was not observed for women, although a superior 5-year CMM-specific survival still exists compared to that of men, motivating a continued need of improved secondary preventive actions for men. 


\section{Summary}

Background: Both patient survival and the proportion of patients diagnosed with thin cutaneous malignant melanoma (CMM) have been steadily rising in Sweden as in most western countries, though the rate of improvement in survival appears to have declined in Sweden at the end of last millennium.

Objectives: To analyse the most recent trends in the distribution of tumour thickness (Tcategory) as well as CMM-specific survival in Swedish patients diagnosed 1997-2011. Methods: This nationwide population-based study included 30590 patients registered in the Swedish Melanoma Register (SMR) and diagnosed with a first primary invasive CMM 1997-2011. The patients were followed through 2012 in the national Cause-ofDeath Register.

Results: Logistic and Cox regression analyses adjusting for age at diagnosis, tumour site, and health care region were carried out. The odds ratio for being diagnosed with thicker tumours was significantly reduced $(\mathrm{P}=0 \cdot 0008)$ and the $\mathrm{CMM}$-specific survival significantly improved in men diagnosed 2007-2011 compared to men diagnosed 19972001 (hazard ratio $=0 \cdot 81 ; 95 \%$ CI $0 \cdot 72-0 \cdot 91, \mathrm{P}=0 \cdot 0009$ ) while the corresponding differences for women were not significant. Women were diagnosed with significantly thicker tumours during 2002-2006 and a tendency towards decreased survival was observed compared to those diagnosed earlier 1997-2001 and later 2007-2011.

Conclusion: In Sweden, the CMMs of men are detected earlier over time and this seems to be followed by an improved CMM-specific survival for men. Women are still diagnosed with considerably thinner tumours and they experience a better survival than men. 
Key words: malignant melanoma; time trend; survival; tumour thickness; population based.

Abbreviations used: SMR: Swedish Melanoma Register; CMM: Cutaneous Malignant Melanoma; CI: Confidence interval; OR: Odds ratios; HR: Hazard ratios 


\section{Introduction}

The incidence of cutaneous malignant melanoma (CMM) in Sweden has been steadily rising since 1958 when the Swedish National Cancer Register was started and made it possible to monitor all cancer. The annual percentage increase in the agestandardised incidence was almost 4\% between the year 1999 and 2008 comparable to most western countries except Australia (1).

In parallel to the increasing incidence of CMM there has been a rising proportion of patients diagnosed at an earlier T-category and the patient survival has improved considerably during the past decades in Sweden $(2,3)$, a trend that has also been observed in several other countries (4-7). In a recent report on patients diagnosed with CMM 1964-2003 in the Nordic countries, Swedish patients had the best survival, but the rate of improvement in survival tended to decline towards the end of period, especially among women (8).

Tumour thickness is the strongest independent prognostic factor and is also the key variable in assessing early detection $(6,7)$. A substantial increase in the proportion of T1 CMM for both men and women between 1976 and 1994 was previously described in a regional Swedish study (2). Swedish national data have not yet been reported. The Swedish Melanoma Register (SMR) currently covers $98 \%$ of all cases of CMM reported to the Swedish National Cancer Register and since 1997 data on T-category have been almost complete.

The aim of this study was to analyse the recent trends in the distribution of tumour thickness (T-category) and CMM-specific survival in Sweden, by comparing patients diagnosed during consecutive 5-year periods: 1997-2001, 2002-2006, and 2007-2011, respectively, using data from the SMR. 


\section{Materials and methods}

\section{Data collection}

Sweden, with about 10 million inhabitants, is divided into 6 health care regions. In each of these regions, regional melanoma groups exist with representatives in plastic and general surgery, dermatology, pathology, oncology, and the Regional Cancer Centre. The latter is responsible for cancer registration and coordination of regional cancer care. Since 1990 the Swedish Melanoma Study Group (SMSG), a multidisciplinary group with members from all health care regions, has prospectively gathered data concerning clinical characteristics, diagnosis, histopathology and primary treatment on all Swedish cases of CMM (comprehensively since 1996) (9). Clinical data are collected by the reporting clinics and monitored/registered at the six Regional Cancer Centres in Sweden within a common data base, the SMR. Histopathological data for all patients are reported prospectively and electronically from the pathology departments into the population-based nationwide SMR. All cases are registered with a unique patient identity-number, which facilitates record linking to official death data (10). SMR is thus a well-documented database with a high coverage. A first report based on SMR data in Sweden 1990-1999 has been published (9). SMR data have recently been used in reports on the prognosis of T1 CMM (11), on level of education and survival (12), and on cohabitation status and survival (13).

During the time period 1997-2011, 31098 patients with CMMs were reported to the SMR. From these, 508 patients (1.6\%) with previous CMMs diagnosed before 1997 were excluded. Among the remaining 30590 patients with first primary invasive CMM $828(2.7 \%)$ lacked information on T-category. 
The following variables from SMR were used in the present study: gender, age at diagnosis, date of diagnosis, tumour site, health care region, and T-category. Date and cause of death until December 31, 2012 were obtained from the Swedish Cause of Death Register.

\section{Statistical analysis}

All statistical analyses were performed for men and women separately. In all multivariate analyses, age was categorised into five groups $(\leq 39,40-54,55-64,65-79$ and $\geq 80$ years). In the age-specific analysis two groups were defined; $<65$ and $\geq 65$ years. In all analyses, tumour thickness was analyzed as a categorical variable grouped according to the AJCC-2002 classification as T1 $(\leq 1 \cdot 0 \mathrm{~mm}), \mathrm{T} 2(1 \cdot 01-2 \cdot 0 \mathrm{~mm}), \mathrm{T} 3$ $(2 \cdot 01-4 \cdot 0 \mathrm{~mm})$ and $\mathrm{T} 4(>4 \cdot 0 \mathrm{~mm})(14)$.

Age- and gender-specific incidence rates per 100000 inhabitants were calculated for each 5-year period of diagnosis.

To evaluate the association between period and T-category at diagnosis a multinomial logistic regression was used with $\mathrm{T} 1 \mathrm{CMMs}$ as reference. The results from the logistic regressions were expressed as odds ratios (OR) with $95 \%$ confidence intervals (CI). Proportional odds models were used in order to calculate P-values for OR trends over T-category. All logistic regression models also included age, tumour site, and health care region to adjust for any potential confounding effects of these variables.

Survival time was calculated from the date of diagnosis (date of diagnostic biopsy or date of pathology report) until date of the event or to the date of censoring. In the survival analyses, death from CMM was selected as the primary event. Censoring was made at the time point of: emigration, diagnosis of a second CMM (during the study period), death from causes other than CMM, or the cut-off date, December 31, 2012. 
CMM-specific survival and CI were estimated using the method of Kaplan and Meier

(15). Cox's proportional hazard regression was used to assess the independent prognostic contribution of period of diagnosis after adjustment for the confounders' age and tumour site. The prognostic impacts were expressed as hazard ratios (HRs) with 95\% CIs. Using stratified Cox regression models the analyses were adjusted for health care region. Patients with missing data on tumour site or T-category were excluded from the multivariable analyses. Statistical significance was indicated by P-values < 0.05. All statistical analyses were performed using SAS v9.3.

\section{Results}

Of the 30590 patients diagnosed with a first primary invasive CMM between 1997 and 2011, $15420(50 \cdot 4 \%)$ were women. During this period, men had a median age of 65 years at diagnosis compared to 61 years for women. The median age at diagnosis increased from 62 years in the period 1997-2001 to 64 years in 2007-2011.

Fig. 1 shows the age-specific incidence per 100000 in the three 5-year periods studied. The graphs demonstrate a similar increase over time periods for all age categories above 30 years both for men and women. Below 30 years of age $(<4 \%$ of the patients) a smaller change is seen.

During 2007-2011 50.7\% of men and 57.4\% of women diagnosed with CMM had T1 CMM compared with 48.4\% and 57.1\% in 1997-2001 (Supplementary Table 1). The T-category distribution for the three periods is illustrated in Fig. 2. In the logistic regression analysis after adjustments for age, tumour site and health care region, there was a statistically significant shift towards thinner tumours during 2007-2011 compared to 1997-2001 for men $(\mathrm{P}=0 \cdot 0008)$ but not for women $(\mathrm{P}=0 \cdot 28)$ (Table 1). This trend towards thinner tumours was seen in both the younger $(\mathrm{P}=0 \cdot 02)$ and older $(\mathrm{P}=0 \cdot 01)$ 
age groups for men. Compared with 1997-2001, the proportion of T4 CMMs decreased significantly in 2007-2011 for younger men and the proportions of T2 and T3 CMM decreased significantly for older men. In men there was a tendency towards a higher proportion of T4 tumours in 2002-2006 which was significant in older men. For women diagnosed between 2002 and 2006, there was a significant shift towards thicker tumours compared to those diagnosed between 1997 and $2001(\mathrm{P}=0 \cdot 02$; Table 1). However, women diagnosed 2007-2011 shifted back towards thinner tumours compared to 2002$2006(P=0 \cdot 002)$.

During a median follow-up time of 4.8 years (range 0-16 years), 2090 men and 1 313 women died from CMM. In unadjusted survival analysis, there was a significant trend towards improved CMM-specific survival over time periods in men but not in women (Fig. 3). Among men diagnosed 1997-2001, the 5-year CMM-specific survival was $84.7 \%$ and $86.8 \%$ among male patients diagnosed $2007-2011$. The corresponding results for women were $91.8 \%$ and $92.5 \%$, respectively (Fig. 3).

In Cox regression analyses adjusted for age, tumour site and health care region, there were significant improvements in CMM-specific survival over time periods for men $(\mathrm{P}$ trend $=0 \cdot 0009$; Table 2). A 19\% lower CMM death rate was found in men diagnosed 2007-2011 compared to men diagnosed 1997-2001, $(\mathrm{HR}=0 \cdot 81 ; 95 \% \mathrm{CI}$ : $0 \cdot 72-0 \cdot 91)$. The improved survival was seen in both the younger $(\mathrm{P}=0 \cdot 01)$ and older $(\mathrm{P}$ $=0.02)$ age groups for men. No significant differences were observed in women, but a tendency towards worse survival were seen in women diagnosed during 2002-2006, $(\mathrm{HR}=1 \cdot 10 ; 95 \% \mathrm{CI}: 0 \cdot 96-1 \cdot 25)$. No significant changes in survival were seen for either men or women comparing patients diagnosed 2002-2006 with patients diagnosed 19972001. In absolute terms the CMM-specific survival was improved from $88 \cdot 3$ (1997- 
2001 ) to $91 \cdot 0 \%$ (2007-2011) for younger men and from $80 \cdot 4$ to $82.3 \%$ for older men. The corresponding change for women was $95 \cdot 1$ to $95 \cdot 3 \%$ for younger women and $86 \cdot 6$ to $88.7 \%$ for older women (Supplementary Fig. 1). CMM-specific survival per Tcategory showed a significant improvement for T3 CMM among men $(69 \cdot 2$ to $72 \cdot 6 \%, \mathrm{P}$ trend $=0.026)$ and for T2 CMM among women $(91.6$ to $95 \cdot 0 \%, \mathrm{P}$ trend $=0.029)$ (Supplementary Fig. 2).

Since there is a correlation between tumour thickness and the histogenetic type it is of interest to note that the proportion of nodular melanomas was lower in the period 2007-2011 than in 1997-2001 (Supplementary Table 2). Furthermore, among nonnodular melanoma the time trend in men towards a more favourable distribution on $\mathrm{T}$ category was still significant (Supplementary Tables 3 and 4). Nodular melanomas showed an opposite trend becoming thicker in the last two time periods among both men and women (Supplementary Tables 5 and 6).

\section{Discussion}

In the present Swedish nationwide study including over 30000 patients diagnosed with a first primary invasive CMM, the most important finding is a shift over time towards thinner tumours for men accompanied by an improved survival. This trend was seen in both younger and older men. The time trends of tumour thickness in CMM on a national level have not previously been studied in Sweden. A previous regional study based on data from 1976-1994 showed a pronounced increase of T1 CMM for both men and women (2). In the present study, the proportion of T1 CMM among women was higher than for men but quite stable over time. In absolute terms, the proportion of T1 CMMs in women below 65 years was $8 \%$ higher than among men in the same age 
group. In addition, the proportion of T4 CMM was lower for women than for men in both age groups. These gender differences may partly be attributed to better skin selfexamination practices and health related behaviours in women resulting in thinner, potentially curable tumours. The improvement seen for men may have several reasons. There have been no directed skin cancer awareness campaigns towards men in Sweden, instead one may speculate that men became more concerned with their health in general leading to change in their care seeking behaviour. Since the improvement towards a $\underline{\text { more favourable distribution of } \mathrm{T} \text { category was seen also for older men one could }}$ speculate whether the increasing use of opportunistic prostate cancer screening by PSA testing might have had a similar positive effect on care-seeking behaviour among older men (via an elevated concern about their health). It has been estimated that at least onethird of all Swedish men aged 50-75 years had a PSA test between 2000 and 2007 (16) and this proportion has continued to increase.

The finding in the present study of a transient trend of thicker tumours in the middle period 2002-2006 is difficult to explain. While women appear to be more affected than men, the confidence intervals are overlapping so the sex difference may be due to chance. If so, one may speculate that the trend to some extent is associated with the changes in the Swedish health care system. In spite of an increasing population, the number of visits to physicians (including general practitioners) decreased slightly in the middle period but increased considerably in the last period.

Recent data from Holland show similar proportions of T1 CMMs as in Sweden. In 2008 among patients aged below 65 years, $51 \%$ of men and $62 \%$ of women had a T1 CMM and the corresponding figures for age 65 years or above were $40 \%$ and $42 \%$, respectively. The gender difference for younger age groups in Holland is consistent with 
present SMR data coinciding with results for older patients (17). Regarding survival trends in Holland, the prognosis in men improved more than in women comparing 2004-2008 with 1999-2003 (6). A long history of governmental supported health cancer awareness campaigns in Australia may have contributed to a plateau in incidence 19962006 and the proportion of T1 CMMs is over 60\% (18). Higher proportions of T1 CMMs have also been reported from a selected US population $(19,20)$.

Tumour thickness is one of the most important variables to be recorded in

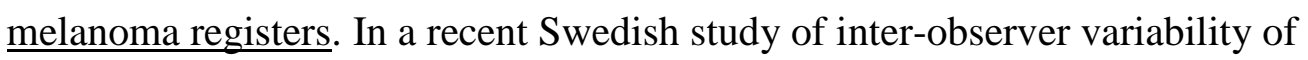
histopathological factors, tumour thickness showed the highest consistency between pathologists (21). Changes over time in tumour thickness could be used as an indicator of subsequent changes in survival (22). The proportion of T1 CMMs can be used as an indicator/proxy to assess the effect of early detection activities. However, in order to better predict changes in survival on a population level, also changes in the upper end of the tumour thickness distribution, e.g. the proportion of T4 CMMs, need to be considered.

The strengths of this study include prospectively registered data and the use of recent population-based information providing a high coverage (98\%) of all diagnosed invasive CMMs in Sweden between 1997 and 2011. Tumour thickness is reported directly from the pathology departments in Sweden and the proportion of missing data $(<3 \%)$ is thus low. We have used tumour thickness since it is the most reliable histological prognostic variable. Other histological variables as tumour ulceration, mitosis and sentinel node status are also important independent prognostic factors in CMM. However, the SMR does not contain complete data during the whole study period concerning these factors. 
In this study, the multivariate analysis of survival for men adjusted for confounders shows a significantly increased survival comparing 2007-2011 with 1997-2001. This could be explained partly by an increasing awareness of skin tumours among men but also that the health care system has focused more on early detection activities. There has been a rapid increase in the incidence of CMM for many years and the effects of primary prevention may take several years to assess. Many patients might have had a sun burn or high UV-exposure in childhood which many years later develop to a CMM (23). Campaigns directed to adults might not lower the CMM incidence, but may lead to diagnosis of thinner tumours improving survival (6). Improved skin examination activities might have an impact on finding slowly growing tumours at an earlier Tcategory, while being ineffective for fast growing tumours (24). Quickly growing nodular CMMs are most abundant in older people and accounts for $45 \%$ of CMM deaths in Sweden. Corresponding data from Australia and USA show that $43 \%$ and $37 \%$, respectively, of CMM deaths are caused by the nodular type $(5,24)$.

This study shows that women have a superior 5-year CMM-specific survival compared to men with $4.3 \%$ among patients aged below 65 years and $6.0 \%$ among patients aged 65 years or above. This difference is mainly due to behavioural factors with women diagnosed earlier and with a lower proportion of T3 and T4 CMM compared to men. Biological sex differences may also to some extent contribute to disparities in survival $(25,26)$. The 5-year CMM-specific survival in younger women is now above $95 \%$ leaving little room for further large improvements. Early detection measures directed to men and older women may improve their survival in a more $\underline{\text { substantial way. Low education and not living with a partner are other factors associated }}$ with a worse prognosis and those groups should be targeted for early detection efforts 
$(12,13)$. There are no data concerning the state of knowledge regarding CMM in the general population. The knowledge in Swedish CMM patients about the importance of early detection is in general comparably good and the media seems to be the most important source of information (27).

In conclusion, the CMMs of men are detected earlier over time and this seems to be followed by an improved CMM-specific survival for men. Women are still diagnosed with considerably thinner tumours and they experience a better survival than men. 


\section{Acknowledgements}

The work was supported by Regional Cancer Center South East in Linköping.

Further contributing Regional Cancer Centers were: Southern region (Lund), Western region (Göteborg), Stockholm-Gotland region (Stockholm), Uppsala-Örebro region (Uppsala) and the Northern region (Umeå). We thank associate professor Hans Starkhammar for his valuable contribution. 


\section{References}

1. $\quad$ Erdmann F, Lortet-Tieulent J, Schuz J, Zeeb H, Greinert R, Breitbart EW, et al. International trends in the incidence of malignant melanoma 1953-2008uare recent generations at higher or lower risk? Int J Cancer. 2013 Jan 15;132(2):385-400.

2. Mansson-Brahme E, Johansson H, Larsson O, Rutqvist LE, Ringborg U. Trends in incidence of cutaneous malignant melanoma in a Swedish population 1976-1994. Acta Oncol. 2002;41(2):138-46.

3. Thorn M, Ponten F, Bergstrom R, Sparen P, Adami HO. Trends in tumour characteristics and survival of malignant melanoma 1960-84: a population-based study in Sweden. Br J Cancer. 1994 Oct;70(4):743-8.

4. Cancer survival and prevalence in Australia: period estimates from 1982 to 2010. Asia Pac J Clin Oncol. 2013;9(1):29-39.

5. Shaikh WR, Xiong M, Weinstock MA. The contribution of nodular subtype to melanoma mortality in the United States, 1978 to 2007. Arch Dermatol. 2012;148(1):30-6.

6. Hollestein LM, van den Akker SA, Nijsten T, Karim-Kos HE, Coebergh JW, de Vries E. Trends of cutaneous melanoma in The Netherlands: increasing incidence rates among all Breslow thickness categories and rising mortality rates since 1989. Ann Oncol. 2012 Feb;23(2):524-30.

7. MacKie RM, Bray C, Vestey J, Doherty V, Evans A, Thomson D, et al. Melanoma incidence and mortality in Scotland 1979-2003. Brit J Cancer. 2007 Jun 4;96(11):1772-7.

8. Tryggvadottir L, Gislum M, Hakulinen T, Klint A, Engholm G, Storm HH, et al. Trends in the survival of patients diagnosed with malignant melanoma of the skin in the Nordic countries 19642003 followed up to the end of 2006. Acta Oncol. 2010 Jun;49(5):665-72.

9. Lindholm C, Andersson R, Dufmats M, Hansson J, Ingvar C, Moller T, et al. Invasive cutaneous malignant melanoma in Sweden, 1990-1999 - A prospective, population-based study of survival and prognostic factors. Cancer-Am Cancer Soc. 2004 Nov 1;101(9):2067-78.

10. Ludvigsson JF, Otterblad-Olausson P, Pettersson BU, Ekbom A. The Swedish personal identity number: possibilities and pitfalls in healthcare and medical research. Eur J Epidemiol. 2009;24(11):659-67.

11. Lyth J, Hansson J, Ingvar C, Mansson-Brahme E, Naredi P, Stierner U, et al. Prognostic subclassifications of $\mathrm{T} 1$ cutaneous melanomas based on ulceration, tumour thickness and Clark's level of invasion: results of a population-based study from the Swedish Melanoma Register. Br J Dermatol. 2013 Apr;168(4):779-86.

12. Eriksson H, Lyth J, Mansson-Brahme E, Frohm-Nilsson M, Ingvar C, Lindholm C, et al. Low level of education is associated with later stage at diagnosis and reduced survival in cutaneous malignant melanoma: A nationwide population-based study in Sweden. Eur J Cancer. 2013 Aug;49(12):2705-16.

13. Eriksson H, Lyth J, Mansson-Brahme E, Frohm-Nilsson M, Ingvar C, Lindholm C, et al. Later stage at diagnosis and worse survival in cutaneous malignant melanoma among men living alone: a nationwide population-based study from sweden. J Clin Oncol. 2014 May 1;32(13):1356-64.

14. Balch CM, Buzaid AC, Soong SJ, Atkins MB, Cascinelli N, Coit DG, et al. Final version of the American Joint Committee on Cancer staging system for cutaneous melanoma. J Clin Oncol. 2001;19(16):3635-48.

15. Kaplan EL, Meier P. Nonparametric Estimation from Incomplete Observations. J Am Stat Assoc. 1958;53(282):457-81.

16. Bratt O, Berglund A, Adolfsson J, Johansson JE, Tornblom M, Stattin P. Prostate cancer diagnosed after prostate-specific antigen testing of men without clinical signs of the disease: a populationbased study from the National Prostate Cancer Register of Sweden. Scand J Urol Nephrol. 2010 Dec;44(6):384-90.

17. Kruijff S, Bastiaannet E, Francken AB, Schaapveld M, van der Aa M, Hoekstra HJ. Breslow thickness in the Netherlands: a population-based study of 40880 patients comparing young and elderly patients. Br J Cancer. 2012 Jul 24;107(3):570-4.

18. Baade P, Meng X, Youlden D, Aitken J, Youl P. Time trends and latitudinal differences in melanoma thickness distribution in Australia, 1990-2006. Int J Cancer. 2012 Jan 1;130(1):170-8.

19. Criscione VD, Weinstock MA. Melanoma thickness trends in the United States, 19882006. J Invest Dermatol. 2010 Mar;130(3):793-7. 
20.

Linos E, Swetter SM, Cockburn MG, Colditz GA, Clarke CA. Increasing burden of melanoma in the United States. J Invest Dermatol. 2009 Jul;129(7):1666-74.

21. Eriksson H, Frohm-Nilsson M, Hedblad MA, Hellborg H, Kanter-Lewensohn L, Krawiec $\mathrm{K}$, et al. Interobserver variability of histopathological prognostic parameters in cutaneous malignant melanoma: impact on patient management. Acta Derm Venereol. 2013 Jul 6;93(4):411-6.

22.

MacKie RM, Hauschild A, Eggermont AMM. Epidemiology of invasive cutaneous melanoma. Ann Oncol. 2009 Aug;20:1-7.

23. Whiteman DC, Whiteman CA, Green AC. Childhood sun exposure as a risk factor for melanoma: a systematic review of epidemiologic studies. Cancer Causes Control. 2001 Jan;12(1):69-82. 24. Mar V, Roberts H, Wolfe R, English DR, Kelly JW. Nodular melanoma: a distinct clinical entity and the largest contributor to melanoma deaths in Victoria, Australia. J Am Acad Dermatol. 2013 Apr;68(4):568-75.

25. Gamba CS, Clarke CA, Keegan TH, Tao L, Swetter SM. Melanoma survival disadvantage in young, non-Hispanic white males compared with females. JAMA Dermatol. 2013 Aug;149(8):912-20.

26. Joosse A, Collette S, Suciu S, Nijsten T, Lejeune F, Kleeberg UR, et al. Superior outcome of women with stage I/II cutaneous melanoma: pooled analysis of four European Organisation for Research and Treatment of Cancer phase III trials. J Clin Oncol. 2012 Jun 20;30(18):2240-7. 27. Blum A, Ingvar C, Avramidis M, von Kannen A, Menzies SW, Olsson H, et al. Time to diagnosis of melanoma: same trend in different continents. J Cutan Med Surg. 2007 Jul-Aug;11(4):13744. 


\section{Figure legends}

Fig. 1 Age-specific incidence of cutaneous malignant melanoma in Sweden per 100000 by gender and period of diagnosis

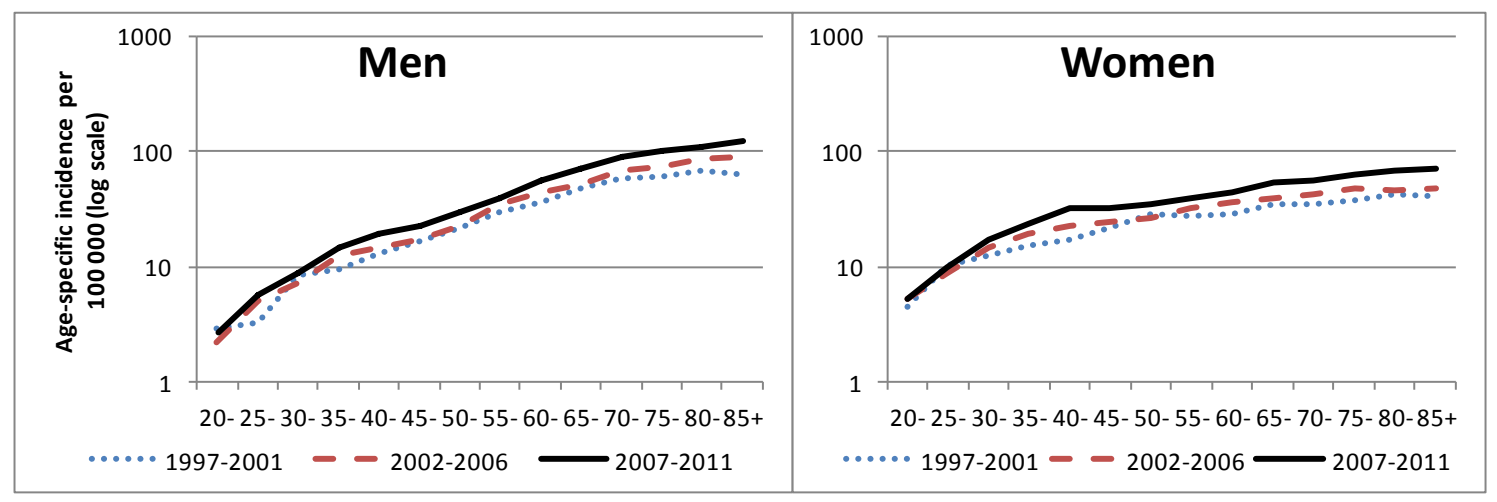


Fig. 2 Distribution of T-category by gender and age for three time periods in 29762 patients diagnosed with primary invasive cutaneous malignant melanoma in Sweden, 1997-2011.

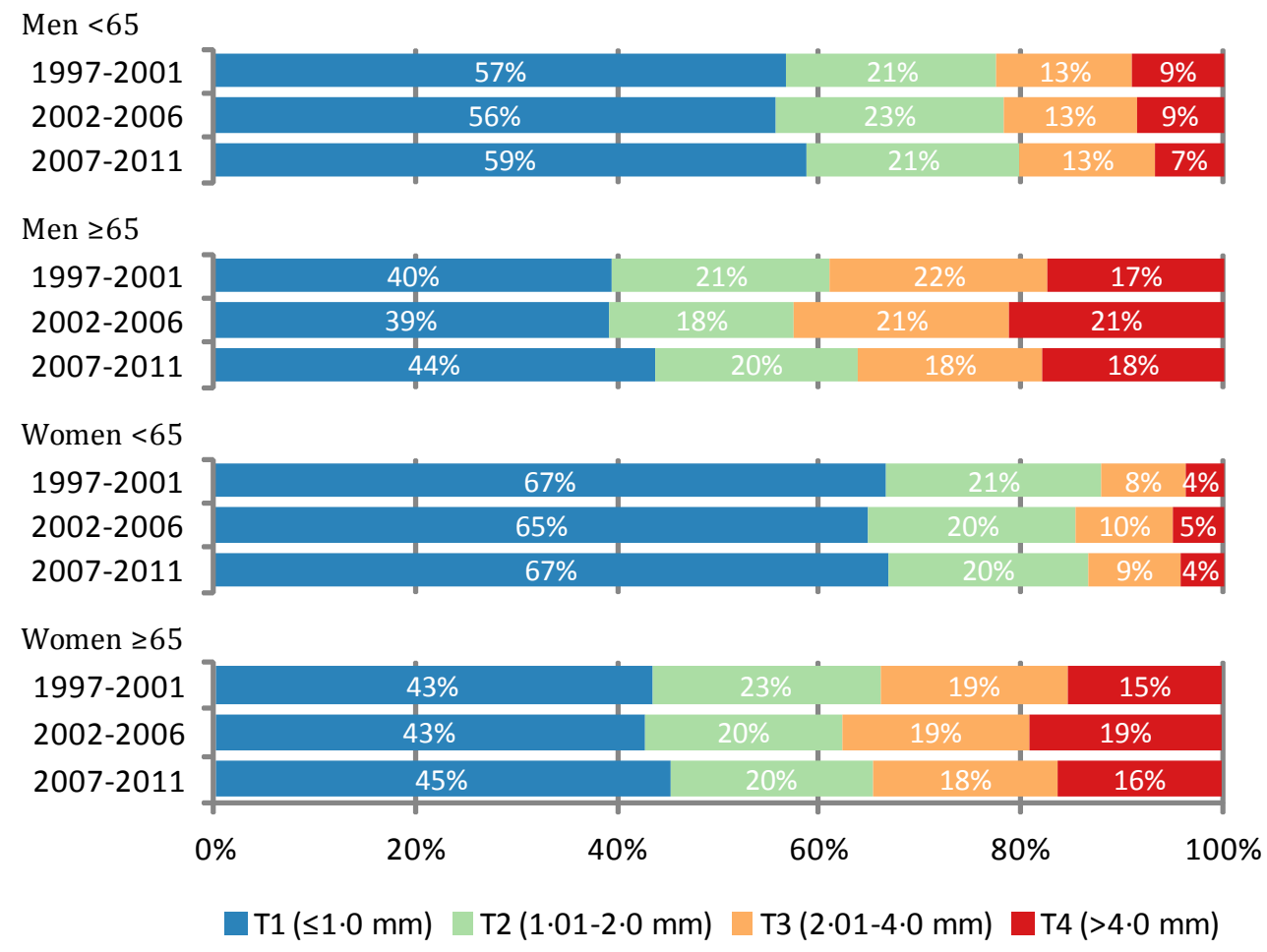


Fig. 3 Kaplan-Meier estimates showing the proportion of patients in Sweden surviving from cutaneous malignant melanoma (CMM) by gender and period of diagnosis $(n=30590)$.

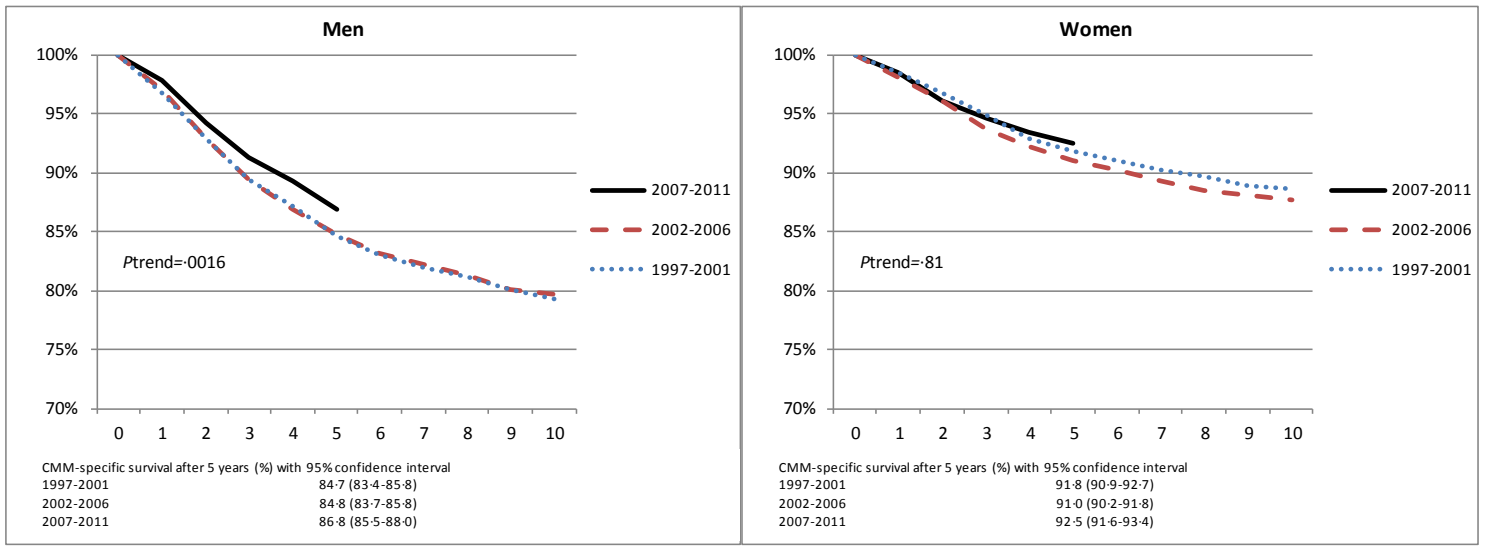


Supplementary Fig. 1 Kaplan-Meier estimates showing the proportion of patients in Sweden surviving from cutaneous malignant melanoma (CMM) by gender, age and period of diagnosis ( $\mathrm{n}=30590)$.

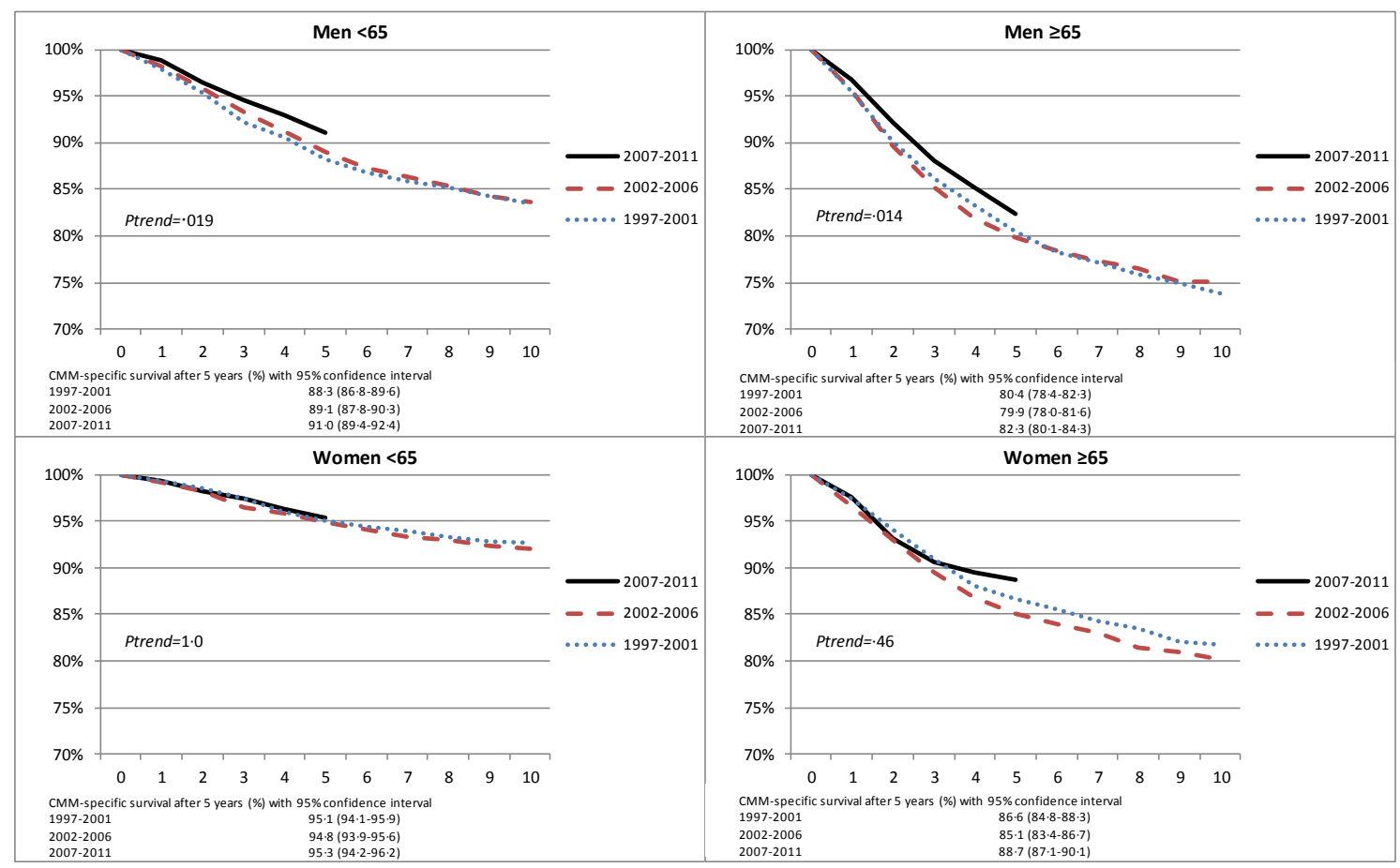


Supplementary Fig. 2 Kaplan-Meier estimates showing the proportion of patients in Sweden surviving from cutaneous malignant melanoma (CMM) by gender, T-category and period of diagnosis ( $\mathrm{n}=30590)$.

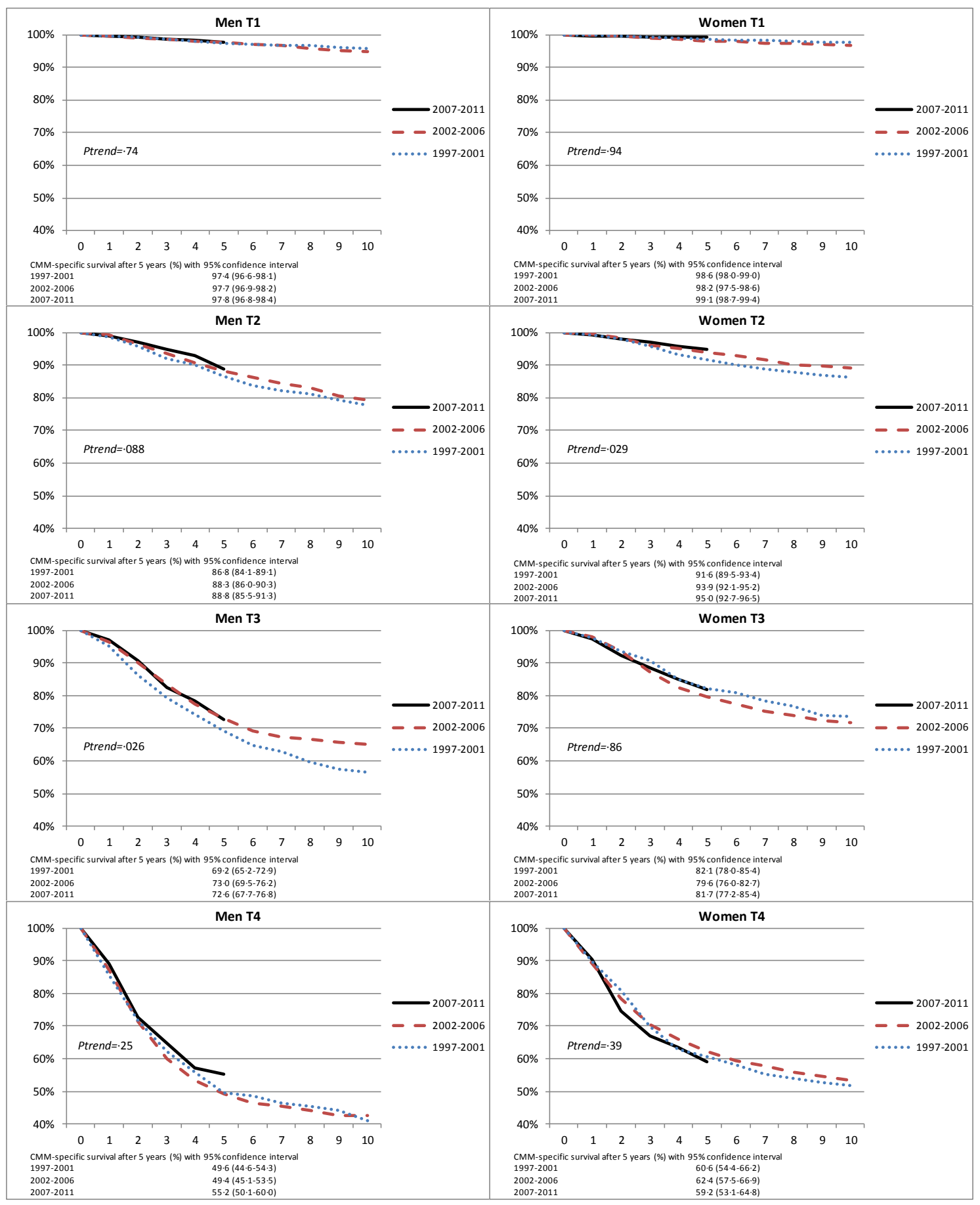




\section{Tables}

Table 1. Association between period of diagnosis and T-category by age and gender in $29624^{\mathrm{a}}$ patients diagnosed with primary invasive cutaneous malignant melanoma in Sweden, 1997-2011

\begin{tabular}{|c|c|c|c|c|c|}
\hline & $\begin{array}{c}\mathrm{T} 1(\leq 1.0 \mathrm{~mm})(\mathrm{ref}) \\
\text { OR }(95 \% \mathrm{CI})^{\mathrm{b}}\end{array}$ & $\begin{array}{c}\text { T2 }(1 \cdot 01-2 \cdot 0 \mathrm{~mm}) \\
\text { OR }(95 \% \mathrm{CI})^{\mathrm{b}}\end{array}$ & $\begin{array}{c}\text { T3 }(2 \cdot 01-4 \cdot 0 \mathrm{~mm}) \\
\text { OR }(95 \% \mathrm{CI})^{\mathrm{b}} \\
\end{array}$ & $\begin{array}{l}\text { T4 }(>4.0 \mathrm{~mm}) \\
\text { OR }(95 \% \mathrm{CI})^{\mathrm{b}}\end{array}$ & $P$ trend $^{\mathrm{c}}$ \\
\hline \multicolumn{6}{|c|}{$2007-2011$ vs $1997-2001$} \\
\hline Men & 1.00 & $0 \cdot 90(0 \cdot 81-1 \cdot 01)$ & $0.83(0.74-0.93)$ & $0.85(0 \cdot 75-0.97)$ & $0 \cdot 0008$ \\
\hline$<65$ & 1.00 & $0 \cdot 97(0 \cdot 84-1 \cdot 12)$ & $0.94(0 \cdot 79-1 \cdot 12)$ & $0 \cdot 70(0 \cdot 56-0 \cdot 88)$ & 0.02 \\
\hline$\geq 65$ & $1 \cdot 00$ & $0.83(0.71-0.97)$ & $0 \cdot 75(0 \cdot 64-0 \cdot 88)$ & $0.91(0 \cdot 77-1 \cdot 07)$ & $0 \cdot 01$ \\
\hline Women & $1 \cdot 00$ & $0.89(0.80-0.99)$ & $0.99(0.87-1 \cdot 13)$ & $1 \cdot 04(0 \cdot 89-1 \cdot 21)$ & $0 \cdot 60$ \\
\hline$<65$ & 1.00 & $0.92(0 \cdot 81-1 \cdot 05)$ & $1 \cdot 07(0 \cdot 89-1 \cdot 30)$ & $1.07(0 \cdot 82-1 \cdot 41)$ & $0 \cdot 89$ \\
\hline$\geq 65$ & 1.00 & $0.84(0.72-0.99)$ & $0.92(0 \cdot 77-1 \cdot 09)$ & $0.99(0 \cdot 82-1 \cdot 20)$ & $0 \cdot 50$ \\
\hline \multicolumn{6}{|c|}{$2002-2006$ vs $1997-2001$} \\
\hline Men & $1 \cdot 00$ & $0.97(0.87-1.09)$ & $0.99(0 \cdot 87-1 \cdot 11)$ & $1.13(0.99-1.29)$ & $0 \cdot 28$ \\
\hline$<65$ & $1 \cdot 00$ & $1.08(0.93-1.26)$ & $0.99(0.82-1 \cdot 19)$ & $0 \cdot 96(0 \cdot 77-1 \cdot 20)$ & $1 \cdot 00$ \\
\hline$\geq 65$ & $1 \cdot 00$ & $0 \cdot 85(0 \cdot 72-1 \cdot 01)$ & $0.98(0 \cdot 83-1 \cdot 15)$ & $1.21(1.01-1.44)$ & $0 \cdot 16$ \\
\hline Women & 1.00 & $0.94(0 \cdot 84-1 \cdot 05)$ & $1 \cdot 08(0 \cdot 94-1 \cdot 23)$ & $1 \cdot 31(1 \cdot 12-1 \cdot 54)$ & 0.02 \\
\hline$<65$ & $1 \cdot 00$ & $0.99(0 \cdot 86-1 \cdot 13)$ & $1.15(0.94-1 \cdot 41)$ & $1.33(1.01-1.76)$ & $0 \cdot 12$ \\
\hline$\geq 65$ & $1 \cdot 00$ & $0 \cdot 87(0 \cdot 73-1 \cdot 04)$ & $0.99(0 \cdot 82-1 \cdot 20)$ & $1.26(1.03-1.53)$ & $0 \cdot 10$ \\
\hline
\end{tabular}

${ }^{\text {a }}$ Exclusion of patients with missing T-category or tumour site

${ }^{\mathrm{b}}$ Model adjusted for age, tumour site and health care region

${ }^{\mathrm{c}}$ Proportional odds model was used to get $\mathrm{p}$ values for trend over T-category 
Table 2. Hazard ratios with corresponding 95\% CIs for melanoma-specific death by age, gender and period of diagnosis in $30444^{\mathrm{a}}$ patients diagnosed with primary invasive cutaneous malignant melanoma in Sweden, 1997-2011

\begin{tabular}{|c|c|c|c|c|}
\hline & $\begin{array}{c}1997-2001 \text { (ref) } \\
\text { HR }(95 \% \mathrm{CI})^{\mathrm{b}}\end{array}$ & 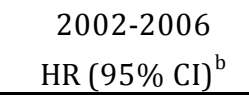 & $\begin{array}{c}2007-2011 \\
\text { HR }(95 \% \mathrm{CI})^{\mathrm{b}}\end{array}$ & $P$ trend \\
\hline Men & $1 \cdot 00$ & $0.99(0.90-1.10)$ & $0.81(0.72-0.91)$ & 0.0009 \\
\hline$<65$ & $1 \cdot 00$ & $0.99(0.85-1.16)$ & $0.75(0.62-0.92)$ & 0.01 \\
\hline$\geq 65$ & $1 \cdot 00$ & $0.99(0.86-1.13)$ & $0.83(0.72-0.97)$ & 0.02 \\
\hline Women & $1 \cdot 00$ & $1 \cdot 10(0.96-1 \cdot 25)$ & $0.94(0.81-1.09)$ & $0 \cdot 54$ \\
\hline$\leq 65$ & $1 \cdot 00$ & $1 \cdot 07(0.87-1 \cdot 32)$ & $0.97(0.75-1.25)$ & 0.94 \\
\hline$\geq 65$ & $1 \cdot 00$ & $1 \cdot 10(0.93-1 \cdot 30)$ & $0.92(0.76-1 \cdot 10)$ & $0 \cdot 39$ \\
\hline
\end{tabular}

${ }^{\mathrm{a}}$ Exclusion of patients with missing tumour site

${ }^{\mathrm{b}}$ Model adjusted for age, tumour site, and health care region 
Supplementary table 1. Distribution of T-category by gender, age and time period in $29762^{\mathrm{a}}$ patients diagnosed with primary invasive cutaneous malignant melanoma in Sweden, 1997-2011

\begin{tabular}{|c|c|c|c|c|c|c|c|c|c|c|}
\hline \multirow[b]{2}{*}{ Tumour thickness } & \multicolumn{5}{|c|}{ Men } & \multicolumn{5}{|c|}{ Women } \\
\hline & $\begin{array}{c}\text { T1 }(\leq 1 \cdot 0 \mathrm{~mm}) \\
\text { No. }(\%)\end{array}$ & $\begin{array}{c}\text { T2 }(1 \cdot 0-2 \cdot 0 \mathrm{~mm}) \\
\text { No. }(\%) \\
\end{array}$ & $\begin{array}{c}\text { T3 }(2 \cdot 0-4 \cdot 0 \mathrm{~mm}) \\
\text { No. }(\%) \\
\end{array}$ & $\begin{array}{c}\text { T4 }(>4.0 \mathrm{~mm}) \\
\quad \text { No. }(\%)\end{array}$ & $\begin{array}{c}\text { Missing } \\
\text { No. }\end{array}$ & $\begin{array}{c}\text { T1 }(\leq 1 \cdot 0 \mathrm{~mm}) \\
\quad \text { No. }(\%) \\
\end{array}$ & $\begin{array}{c}\text { T2 }(1 \cdot 0-2 \cdot 0 \mathrm{~mm}) \\
\text { No. }(\%) \\
\end{array}$ & $\begin{array}{c}\text { T3 }(2 \cdot 0-4 \cdot 0 \mathrm{~mm}) \\
\text { No. }(\%) \\
\end{array}$ & $\begin{array}{c}\text { T4 }(>4.0 \mathrm{~mm}) \\
\text { No. }(\%)\end{array}$ & $\begin{array}{l}\text { Missing } \\
\text { No. }\end{array}$ \\
\hline \multicolumn{11}{|l|}{ All patients } \\
\hline 1997-2001 & $1826(48 \cdot 4)$ & $799(21 \cdot 2)$ & $657(17 \cdot 4)$ & $494(13 \cdot 1)$ & 119 & $2231(57 \cdot 1)$ & $853(21 \cdot 8)$ & $490(12 \cdot 6)$ & $330(8 \cdot 5)$ & 143 \\
\hline $2002-2006$ & $2203(47 \cdot 6)$ & $951(20 \cdot 5)$ & $792(17 \cdot 1)$ & $685(14 \cdot 8)$ & 139 & 2615 (55.9) & $941(20 \cdot 1)$ & $619(13 \cdot 2)$ & $504(10 \cdot 8)$ & 136 \\
\hline 2007-2011 & $3237(50 \cdot 7)$ & $1316(20 \cdot 6)$ & $1015(15 \cdot 9)$ & $812(12 \cdot 7)$ & 125 & $3666(57 \cdot 4)$ & $1276(20 \cdot 0)$ & $844(13 \cdot 2)$ & $606(9 \cdot 5)$ & 166 \\
\hline \multicolumn{11}{|l|}{ Age } \\
\hline \multicolumn{11}{|l|}{$<65$} \\
\hline $1997-2001$ & $1095(56 \cdot 8)$ & $402(20 \cdot 9)$ & $257(13 \cdot 3)$ & $174(9 \cdot 0)$ & 53 & $1537(66 \cdot 6)$ & $492(21 \cdot 3)$ & $191(8 \cdot 3)$ & $88(3 \cdot 8)$ & 63 \\
\hline $2002-2006$ & $1317(55 \cdot 7)$ & $533(22 \cdot 5)$ & $312(13 \cdot 2)$ & $204(8 \cdot 6)$ & 51 & $1796(64.9)$ & $567(20 \cdot 5)$ & $263(9 \cdot 5)$ & $140(5 \cdot 1)$ & 61 \\
\hline 2007-2011 & $1757(58 \cdot 7)$ & $636(21 \cdot 2)$ & $396(13 \cdot 2)$ & $205(6 \cdot 8)$ & 59 & $2397(66 \cdot 8)$ & $710(19.8)$ & $329(9 \cdot 2)$ & $152(4 \cdot 2)$ & 84 \\
\hline \multicolumn{11}{|l|}{$\geq 65$} \\
\hline 1997-2001 & $731(39 \cdot 6)$ & $397(21 \cdot 5)$ & $400(21 \cdot 6)$ & $320(17 \cdot 3)$ & 66 & $694(43 \cdot 5)$ & $361(22 \cdot 6)$ & $299(18 \cdot 7)$ & $242(15 \cdot 2)$ & 80 \\
\hline $2002-2006$ & $886(39 \cdot 1)$ & $418(18 \cdot 5)$ & $480(21 \cdot 2)$ & $481(21 \cdot 2)$ & 88 & $819(42 \cdot 8)$ & $374(19 \cdot 6)$ & $356(18 \cdot 6)$ & $364(19 \cdot 0)$ & 75 \\
\hline 2007-2011 & $1480(43 \cdot 7)$ & $680(20 \cdot 1)$ & $619(18 \cdot 3)$ & $607(17.9)$ & 66 & $1269(45 \cdot 3)$ & $566(20 \cdot 2)$ & $515(18 \cdot 4)$ & $454(16 \cdot 2)$ & 82 \\
\hline
\end{tabular}

${ }^{\mathrm{a}}$ Exclusion of patients with missing T-category 
Supplementary table 2. Distribution of histogenetic type by gender, age and time period in $30590^{\mathrm{a}}$ patients diagnosed with primary invasive cutaneous malignant melanoma in Sweden $1997-2011$

\begin{tabular}{|c|c|c|c|c|c|c|c|c|c|c|c|c|}
\hline \multirow[b]{2}{*}{ Tumour thickness } & \multicolumn{6}{|c|}{ Men } & \multicolumn{6}{|c|}{ Women } \\
\hline & $\begin{array}{c}\text { SSM } \\
\text { No. }(\%)\end{array}$ & $\begin{array}{c}\text { LMM } \\
\text { No. (\%) }\end{array}$ & $\begin{array}{c}\text { NM } \\
\text { No. (\%) }\end{array}$ & $\begin{array}{c}\text { ALM } \\
\text { No. }(\%) \\
\end{array}$ & $\begin{array}{l}\text { Other type } \\
\text { No. }(\%)\end{array}$ & $\begin{array}{c}\text { Missing } \\
\text { No. }\end{array}$ & $\begin{array}{c}\text { SSM } \\
\text { No. (\%) }\end{array}$ & $\begin{array}{c}\text { LMM } \\
\text { No. (\%) }\end{array}$ & $\begin{array}{c}\text { NM } \\
\text { No. (\%) }\end{array}$ & $\begin{array}{c}\text { ALM } \\
\text { No. }(\%)\end{array}$ & $\begin{array}{l}\text { Other type } \\
\text { No. }(\%)\end{array}$ & $\begin{array}{l}\text { Missing } \\
\text { No. }\end{array}$ \\
\hline \multicolumn{13}{|l|}{ All patients } \\
\hline $1997-2001$ & $2231(57.7)$ & $239(6.2)$ & $858(22.2)$ & $62(1.6)$ & 477 (12.3) & 28 & $2394(59.7)$ & $266(6.6)$ & $691(17.2)$ & $87(2.2)$ & $571(14.2)$ & 38 \\
\hline $2002-2006$ & $2602(55.1)$ & $296(6.3)$ & $1088(23.1)$ & $40(0.8)$ & $693(14.7)$ & 51 & $2853(60.1)$ & $334(7.0)$ & $852(18.0)$ & $64(1.3)$ & $641(13.5)$ & 71 \\
\hline 2007-2011 & $3704(59.0)$ & $463(7.4)$ & $1272(20.3)$ & $56(0.9)$ & $783(12.5)$ & 227 & 4004 (63.6) & $436(6.9)$ & 990 (15.7) & $94(1.5)$ & $776(12.3)$ & 258 \\
\hline \multicolumn{13}{|l|}{ Age } \\
\hline \multicolumn{13}{|l|}{$<65$} \\
\hline $1997-2001$ & $1311(66.6)$ & $49(2.5)$ & $331(16.8)$ & $25(1.3)$ & $253(12.8)$ & 12 & $1607(68.4)$ & $54(2.3)$ & 304 (12.9) & $31(1.3)$ & $352(15.0)$ & 23 \\
\hline $2002-2006$ & $1545(64.4)$ & $77(3.2)$ & $428(17.8)$ & $20(0.8)$ & $330(13.8)$ & 17 & $1939(69.4)$ & $98(3.5)$ & $355(12.7)$ & $29(1.0)$ & $373(13.4)$ & 33 \\
\hline $2007-2011$ & $1979(67.2)$ & $130(4.4)$ & 435 (14.8) & $22(0.7)$ & $381(12.9)$ & 106 & 2545 (72.6) & $85(2.4)$ & $385(11.0)$ & $41(1.2)$ & $449(12.8)$ & 167 \\
\hline \multicolumn{13}{|l|}{$\geq 65$} \\
\hline $1997-2001$ & $920(48.5)$ & $190(10.0)$ & $527(27.8)$ & $37(1.9)$ & $224(11.8)$ & 16 & $787(47.4)$ & $212(12.8)$ & $387(23.3)$ & $56(3.4)$ & 219 (13.2) & 15 \\
\hline $2002-2006$ & $1057(45.6)$ & $219(9.4)$ & $660(28.5)$ & $20(0.9)$ & $363(15.7)$ & 34 & 914 (46.9) & $236(12.1)$ & $497(25.5)$ & $35(1.8)$ & $268(13.7)$ & 38 \\
\hline $2007-2011$ & $1725(51.8)$ & $333(10.0)$ & $837(25.1)$ & $34(1.0)$ & $402(12.1)$ & 121 & $1459(52.2)$ & 351 (12.6) & $605(21.6)$ & $53(1.9)$ & 327 (11.7) & 91 \\
\hline
\end{tabular}


Supplementary table 3. Distribution of T-category by gender, age and time period in $24084^{\mathrm{a}}$ patients diagnosed with non_nodular primary invasive cutaneous malignant melanoma in Sweden, 1997-2011

Men

Women

\begin{tabular}{|c|c|c|c|c|c|c|c|c|c|c|}
\hline \multirow[b]{2}{*}{ Tumour thickness } & & \\
\hline & $\begin{array}{l}\text { T1 }(\leq 1 \cdot 0 \mathrm{~mm}) \\
\text { No. (\%) }\end{array}$ & $\begin{array}{c}\text { T2 }(1 \cdot 0-2 \cdot 0 \mathrm{~mm}) \\
\text { No. }(\%)\end{array}$ & $\begin{array}{c}\text { T3 }(2 \cdot 0-4 \cdot 0 \mathrm{~mm}) \\
\text { No. (\%) }\end{array}$ & $\begin{array}{l}\text { T4 }(>4 \cdot 0 \mathrm{~mm}) \\
\quad \text { No. }(\%)\end{array}$ & $\begin{array}{l}\text { Missing } \\
\text { No. }\end{array}$ & $\begin{array}{l}\text { T1 }(\leq 1 \cdot 0 \mathrm{~mm}) \\
\text { No. }(\%) \\
\end{array}$ & $\begin{array}{c}\text { T2 }(1 \cdot 0-2 \cdot 0 \mathrm{~mm}) \\
\text { No. (\%) }\end{array}$ & $\begin{array}{c}\text { T3 }(2 \cdot 0-4 \cdot 0 \mathrm{~mm}) \\
\text { No. }(\%)\end{array}$ & $\begin{array}{c}\text { T4 (>4.0 mm) } \\
\text { No. (\%) }\end{array}$ & $\begin{array}{c}\text { Missing } \\
\text { No. }\end{array}$ \\
\hline \multicolumn{11}{|l|}{ All patients } \\
\hline $1997-2001$ & $1764(60.1)$ & $633(21.6)$ & $341(11.6)$ & $195(6.6)$ & 104 & $2159(67.0)$ & $660(20.5)$ & $270(8.4)$ & $134(4.2)$ & 133 \\
\hline $2002-2006$ & $2146(60.3)$ & $758(21.3)$ & $403(11.3)$ & $252(7.1)$ & 123 & $2541(66.3)$ & 763 (19.9) & 325 (8.5) & 204 (5.3) & 130 \\
\hline 2007-2011 & $3170(61.9)$ & $1086(21.2)$ & $552(10.8)$ & $314(6.1)$ & 111 & $3580(66.1)$ & $1089(20.1)$ & $480(8.9)$ & $265(4.9)$ & 154 \\
\hline \multicolumn{11}{|l|}{ Age } \\
\hline \multicolumn{11}{|l|}{$<65$} \\
\hline $1997-2001$ & $1059(66.1)$ & $329(20.5)$ & $134(8.4)$ & $81(5.1)$ & 47 & $1487(74.1)$ & $380(18.9)$ & $101(5.0)$ & $39(1.9)$ & 60 \\
\hline $2002-2006$ & $1283(65.9)$ & 427 (21.9) & $171(8.8)$ & $66(3.4)$ & 42 & $1751(72.5)$ & $460(19.1)$ & $141(5.8)$ & $62(2.6)$ & 58 \\
\hline 2007-2011 & $1720(67.1)$ & $524(20.4)$ & $236(9.2)$ & $83(3.2)$ & 55 & 2343 (73.1) & $613(19.1)$ & $185(5.8)$ & $63(2.0)$ & 83 \\
\hline \multicolumn{11}{|l|}{$\geq 65$} \\
\hline $1997-2001$ & $705(53.0)$ & $304(22.9)$ & 207 (15.6) & $114(8.6)$ & 57 & $672(55.3)$ & $280(23.0)$ & 169 (13.9) & $95(7.8)$ & 73 \\
\hline $2002-2006$ & $863(53.5)$ & $331(20.5)$ & $232(14.4)$ & $186(11.5)$ & 81 & $790(55.7)$ & $303(21.4)$ & $184(13.0)$ & $142(10.0)$ & 72 \\
\hline 2007-2011 & $1450(56.7)$ & $562(22.0)$ & $316(12.3)$ & $231(9.0)$ & 56 & $1237(56.0)$ & $476(21.5)$ & 295 (13.3) & $202(9.1)$ & 71 \\
\hline
\end{tabular}

${ }^{a}$ Exclusion of patients with missing T-category 
Supplementary table 4. Association between period of diagnosis and T-category by age and gender in $23974^{\text {a }}$ patients diagnosed with non-nodular primary invasive cutaneous malignant melanoma in Sweden, 1997-2011

\begin{tabular}{|c|c|c|c|c|c|}
\hline & $\begin{array}{c}\mathrm{T} 1(\leq 1.0 \mathrm{~mm})(\mathrm{ref}) \\
\text { OR }(95 \% \mathrm{CI})^{\mathrm{b}}\end{array}$ & $\begin{array}{c}\text { T2 }(1 \cdot 01-2 \cdot 0 \mathrm{~mm}) \\
\text { OR }(95 \% \mathrm{CI})^{\mathrm{b}} \\
\end{array}$ & $\begin{array}{c}\text { T3 }(2 \cdot 01-4 \cdot 0 \mathrm{~mm}) \\
\text { OR }(95 \% \mathrm{CI})^{\mathrm{b}}\end{array}$ & $\begin{array}{l}\text { T4 }(>4.0 \mathrm{~mm}) \\
\text { OR }(95 \% \mathrm{CI})^{\mathrm{b}}\end{array}$ & $P$ trend $^{\mathrm{c}}$ \\
\hline \multicolumn{6}{|c|}{$2007-2011$ vs $1997-2001$} \\
\hline Men & $1 \cdot 00$ & $0.93(0.83-1.04)$ & $0 \cdot 87(0 \cdot 75-1 \cdot 01)$ & $0 \cdot 85(0 \cdot 70-1 \cdot 04)$ & 0.02 \\
\hline$<65$ & $1 \cdot 00$ & $0.96(0 \cdot 82-1 \cdot 13)$ & $1 \cdot 07(0 \cdot 85-1 \cdot 35)$ & $0.61(0.44-0.84)$ & $0 \cdot 21$ \\
\hline$\geq 65$ & $1 \cdot 00$ & $0 \cdot 88(0 \cdot 74-1 \cdot 04)$ & $0.74(0.60-0.90)$ & $1 \cdot 01(0 \cdot 78-1 \cdot 29)$ & 0.05 \\
\hline Women & $1 \cdot 00$ & $0.97(0.87-1.08)$ & $1 \cdot 01(0 \cdot 86-1 \cdot 19)$ & $1 \cdot 11(0 \cdot 89-1 \cdot 39)$ & $0 \cdot 80$ \\
\hline$<65$ & $1 \cdot 00$ & $1 \cdot 01(0 \cdot 87-1 \cdot 17)$ & $1 \cdot 13(0 \cdot 88-1 \cdot 45)$ & $1 \cdot 01(0 \cdot 67-1 \cdot 51)$ & $0 \cdot 60$ \\
\hline$\geq 65$ & $1 \cdot 00$ & $0 \cdot 91(0 \cdot 76-1 \cdot 09)$ & $0.93(0 \cdot 75-1 \cdot 15)$ & $1 \cdot 12(0 \cdot 85-1 \cdot 47)$ & $0 \cdot 79$ \\
\hline \multicolumn{6}{|c|}{$2002-2006$ vs $1997-2001$} \\
\hline Men & $1 \cdot 00$ & $0.96(0.85-1.09)$ & $0.96(0 \cdot 82-1 \cdot 13)$ & $1 \cdot 07(0 \cdot 87-1 \cdot 31)$ & $0 \cdot 91$ \\
\hline$<65$ & $1 \cdot 00$ & $1 \cdot 05(0 \cdot 89-1 \cdot 24)$ & $1 \cdot 03(0 \cdot 81-1 \cdot 32)$ & $0.67(0.48-0.94)$ & $0 \cdot 53$ \\
\hline$\geq 65$ & $1 \cdot 00$ & $0 \cdot 87(0 \cdot 72-1 \cdot 05)$ & $0 \cdot 91(0 \cdot 74-1 \cdot 13)$ & $1 \cdot 34(1 \cdot 03-1 \cdot 74)$ & $0 \cdot 71$ \\
\hline Women & $1 \cdot 00$ & $0.98(0 \cdot 87-1.10)$ & $1 \cdot 02(0 \cdot 85-1 \cdot 21)$ & $1 \cdot 29(1.02-1 \cdot 62)$ & $0 \cdot 34$ \\
\hline$<65$ & $1 \cdot 00$ & $1 \cdot 02(0 \cdot 87-1 \cdot 19)$ & $1 \cdot 15(0 \cdot 88-1 \cdot 50)$ & $1 \cdot 33(0 \cdot 89-2 \cdot 01)$ & $0 \cdot 24$ \\
\hline$\geq 65$ & $1 \cdot 00$ & $0.91(0 \cdot 75-1 \cdot 11)$ & $0 \cdot 91(0 \cdot 72-1 \cdot 15)$ & $1 \cdot 22(0.92-1 \cdot 63)$ & $0 \cdot 91$ \\
\hline
\end{tabular}

${ }^{\text {a }}$ Exclusion of patients with missing T-category or tumour site

${ }^{\mathrm{b}}$ Model adjusted for age, tumour site and health care region

${ }^{\mathrm{c}}$ Proportional odds model was used to get $\mathrm{p}$ values for trend over T-category 
Supplementary table 5. Distribution of T-category by gender, age and time period in $5678^{\mathrm{a}}$ patients diagnosed with nodular (NM) primary invasive cutaneous malignant melanoma in Sweden, 1997-2011

Men

Women

\begin{tabular}{|c|c|c|c|c|c|c|c|c|c|c|}
\hline \multirow[b]{2}{*}{ Tumour thickness } & & \\
\hline & $\begin{array}{c}\text { T1 }(\leq 1 \cdot 0 \mathrm{~mm}) \\
\text { No. }(\%)\end{array}$ & $\begin{array}{c}\mathrm{T} 2(1 \cdot 0-2 \cdot 0 \mathrm{~mm}) \\
\text { No. }(\%) \\
\end{array}$ & $\begin{array}{c}\text { T3 }(2 \cdot 0-4 \cdot 0 \mathrm{~mm}) \\
\text { No. }(\%) \\
\end{array}$ & $\begin{array}{c}\text { T4 }(>4.0 \mathrm{~mm}) \\
\quad \text { No. }(\%) \\
\end{array}$ & $\begin{array}{c}\text { Missing } \\
\text { No. } \\
\end{array}$ & $\begin{array}{c}\text { T1 }(\leq 1 \cdot 0 \mathrm{~mm}) \\
\text { No. }(\%) \\
\end{array}$ & $\begin{array}{c}\mathrm{T} 2(1 \cdot 0-2 \cdot 0 \mathrm{~mm}) \\
\text { No. }(\%)\end{array}$ & $\begin{array}{c}\text { T3 }(2 \cdot 0-4 \cdot 0 \mathrm{~mm}) \\
\text { No. }(\%) \\
\end{array}$ & $\begin{array}{c}\text { T4 }(>4.0 \mathrm{~mm}) \\
\text { No. }(\%)\end{array}$ & $\begin{array}{c}\text { Missing } \\
\text { No. } \\
\end{array}$ \\
\hline \multicolumn{11}{|l|}{ All patients } \\
\hline 1997-2001 & $62(7.4)$ & 166 (19.7) & $316(37.5)$ & $299(35.5)$ & 15 & $72(10.6)$ & $193(28.3)$ & $220(32.3)$ & $196(28.8)$ & 10 \\
\hline $2002-2006$ & $57(5.3)$ & $193(18.0)$ & 389 (36.3) & $433(40.4)$ & 16 & $74(8.7)$ & $178(21.0)$ & 294 (34.8) & $300(35.5)$ & 6 \\
\hline 2007-2011 & $67(5.3)$ & 230 (18.3) & 463 (36.8) & $498(39.6)$ & 14 & $86(8.8)$ & $187(19.1)$ & 364 (37.2) & 341 (34.9) & 12 \\
\hline \multicolumn{11}{|l|}{ Age } \\
\hline \multicolumn{11}{|l|}{$<65$} \\
\hline 1997-2001 & $36(11.1)$ & $73(22.5)$ & $123(37.8)$ & $93(28.6)$ & 6 & $50(16.6)$ & $112(37.2)$ & $90(29.9)$ & $49(16.3)$ & 3 \\
\hline $2002-2006$ & $34(8.1)$ & $106(25.3)$ & $141(33.7)$ & $138(32.9)$ & 9 & 45 (12.8) & $107(30.4)$ & $122(34.7)$ & $78(22.2)$ & 3 \\
\hline 2007-2011 & 37 (8.6) & $112(26.0)$ & $160(37.1)$ & $122(28.3)$ & 4 & 54 (14.1) & 97 (25.3) & 144 (37.5) & $89(23.2)$ & 1 \\
\hline \multicolumn{11}{|l|}{$\geq 65$} \\
\hline $1997-2001$ & $26(5.0)$ & $93(18.0)$ & $193(37.3)$ & $206(39.8)$ & 9 & $22(5.8)$ & $81(21.3)$ & $130(34.2)$ & $147(38.7)$ & 7 \\
\hline $2002-2006$ & $23(3.5)$ & 87 (13.3) & 248 (38.0) & $295(45.2)$ & 7 & $29(5.9)$ & $71(14.4)$ & $172(34.8)$ & $222(44.9)$ & 3 \\
\hline 2007-2011 & $30(3.6)$ & 118 (14.3) & 303 (36.6) & $376(45.5)$ & 10 & $32(5.4)$ & $90(15.2)$ & $220(37.0)$ & $252(42.4)$ & 11 \\
\hline
\end{tabular}

${ }^{a}$ Exclusion of patients with missing T-category 
Supplementary table 6. Association between period of diagnosis and T-category by age and gender in $5650^{\mathrm{a}}$ patients diagnosed with nodular (NM) primary invasive cutaneous malignant melanoma in Sweden, 1997-2011

\begin{tabular}{|c|c|c|c|c|c|}
\hline & $\begin{array}{c}\mathrm{T} 1(\leq 1.0 \mathrm{~mm})(\mathrm{ref}) \\
\mathrm{OR}(95 \% \mathrm{CI})^{\mathrm{b}}\end{array}$ & $\begin{array}{c}\text { T2 }(1 \cdot 01-2 \cdot 0 \mathrm{~mm}) \\
\text { OR }(95 \% \mathrm{CI})^{\mathrm{b}} \\
\end{array}$ & $\begin{array}{l}\text { T3 }(2 \cdot 01-4 \cdot 0 \mathrm{~mm}) \\
\text { OR }(95 \% \mathrm{CI})^{\mathrm{b}} \\
\end{array}$ & $\begin{array}{l}\text { T4 }(>4 \cdot 0 \mathrm{~mm}) \\
\text { OR }(95 \% \mathrm{CI})^{\mathrm{b}}\end{array}$ & $P$ trend $^{\mathrm{c}}$ \\
\hline \multicolumn{6}{|c|}{$2007-2011$ vs $1997-2001$} \\
\hline Men & $1 \cdot 00$ & $1.27(0.85-1.90)$ & $1.34(0.91-1.96)$ & $1.44(0.98-2 \cdot 12)$ & $0 \cdot 11$ \\
\hline$<65$ & $1 \cdot 00$ & $1 \cdot 51(0 \cdot 86-2 \cdot 65)$ & $1 \cdot 31(0 \cdot 77-2 \cdot 23)$ & $1 \cdot 33(0 \cdot 77-2 \cdot 30)$ & $0 \cdot 94$ \\
\hline$\geq 65$ & $1 \cdot 00$ & $1.07(0.59-1.94)$ & $1 \cdot 33(0 \cdot 76-2 \cdot 33)$ & $1 \cdot 45(0 \cdot 83-2 \cdot 55)$ & 0.05 \\
\hline Women & $1 \cdot 00$ & $0.79(0.54-1 \cdot 15)$ & $1 \cdot 25(0 \cdot 87-1 \cdot 79)$ & $1.32(0.91-1.93)$ & 0.003 \\
\hline$<65$ & $1 \cdot 00$ & $0 \cdot 80(0 \cdot 50-1 \cdot 30)$ & $1 \cdot 34(0 \cdot 83-2 \cdot 16)$ & $1 \cdot 61(0.95-2 \cdot 76)$ & 0.005 \\
\hline$\geq 65$ & $1 \cdot 00$ & $0.72(0 \cdot 39-1 \cdot 35)$ & $1 \cdot 06(0 \cdot 59-1 \cdot 91)$ & $1.08(0.60-1.96)$ & $0 \cdot 12$ \\
\hline \multicolumn{6}{|c|}{$2002-2006$ vs $1997-20$} \\
\hline Men & $1 \cdot 00$ & $1.29(0 \cdot 85-1.96)$ & $1 \cdot 37(0 \cdot 92-2 \cdot 04)$ & $1 \cdot 60(1 \cdot 07-2 \cdot 39)$ & 0.02 \\
\hline$<65$ & $1 \cdot 00$ & $1 \cdot 55(0 \cdot 88-2 \cdot 72)$ & $1 \cdot 25(0 \cdot 73-2 \cdot 14)$ & $1 \cdot 64(0 \cdot 94-2 \cdot 84)$ & $0 \cdot 27$ \\
\hline$\geq 65$ & $1 \cdot 00$ & $1.06(0 \cdot 56-2 \cdot 00)$ & $1.42(0 \cdot 78-2 \cdot 59)$ & $1.54(0.85-2 \cdot 79)$ & 0.03 \\
\hline Women & $1 \cdot 00$ & $0.90(0 \cdot 61-1 \cdot 32)$ & $1 \cdot 28(0 \cdot 88-1 \cdot 87)$ & $1 \cdot 50(1 \cdot 02-2 \cdot 21)$ & 0.0005 \\
\hline$<65$ & $1 \cdot 00$ & $1.08(0 \cdot 67-1.77)$ & $1.46(0 \cdot 89-2 \cdot 39)$ & $1 \cdot 76(1 \cdot 01-3 \cdot 04)$ & 0.02 \\
\hline$\geq 65$ & $1 \cdot 00$ & $0 \cdot 65(0 \cdot 34-1 \cdot 23)$ & $0.99(0 \cdot 54-1 \cdot 81)$ & $1 \cdot 16(0 \cdot 64-2 \cdot 12)$ & 0.01 \\
\hline
\end{tabular}

${ }^{\mathrm{a}}$ Exclusion of patients with missing T-category or tumour site

${ }^{\mathrm{b}}$ Model adjusted for age, tumour site and health care region

${ }^{\mathrm{c}}$ Proportional odds model was used to get $\mathrm{p}$ values for trend over T-category 